\section{REVISTA CIENTÍFICA RURAL}

ISSN: $1413-8263 \quad 2525-6912$
Revista

Técnico-Científica

\title{
UTILIZAÇÃO DE RESÍDUOS DE FILETAGEM DE TILÁPIA NA TECNOLOGIA DE ALIMENTOS: UMA REVISÃO
}

Rafael Gomes Abreu Bacelar ${ }^{1}$, Maria Christina Sanches Muratori²

\author{
1'Doutorando do Programa de Pós-Graduação em Ciência Animal da Universidade Federal do Piauí, ²Professora \\ Doutora do curso de Medicina Veterinária da Universidade Federal do Piauí.
}

RESUMO: A tilápia do Nilo é uma das espécies mais cultivadas no mundo, seu rendimento de filé pode atingir entre 30 e $40 \%$ do peso do animal. O resíduo de pescado é um termo referente aos subprodutos resultantes do processamento de pescados. Com relação ao peixe, o material residual é constituído por sobras obtidas do processamento de filés ou outros cortes, que inclui a carne aderida aos ossos, cabeça, pele, ossos, escamas e vísceras. Objetivou-se realizar uma revisão sobre a aplicação dos resíduos de filetagem de tilápia na tecnologia de alimentos. E com esse estudo, conclui-se que a utilização dos resíduos de filetagem de tilápia na tecnologia de alimentos tem como proposito minimizar as perdas econômicas das indústrias, diminuição do impacto ambiental e também a oportunidade de inserir o peixe na culinária através do desenvolvimento de produtos.

Palavras-chave: Oreochromis niloticus, peixe, Carne Mecanicamente Separada, produtos.

\section{USE OF TILAPIA RESIDUE IN FOOD TECHNOLOGY: A REVIEW}

ABSTRACT: The Nile tilapia is one of the most cultivated species in the world, its fillet yield can reach between 30 and $40 \%$ of the animal's weight. Fish waste is a term referring to by-products resulting from fish processing. With regard to fish, the residual material consists of remains obtained from the processing of fillets or other cuts that result in remains of meat, head, skin, bones, scales and viscera. The objective was to conduct a review on the application of tilapia 
filleting residues in food technology. And with this study, it is concluded that the use of tilapia filleting residues in food technology is intended to minimize the economic losses of industries, to reduce the environmental impact and also the opportunity to insert fish in cooking through product development.

Keywords: Oreochromis niloticus, fish, Mechanically Separated Meat, products.

\section{INTRODUÇÃO}

O crescimento da produção aquícola mundial ao longo dos anos, vem gerando uma grande quantidade de resíduos pelas indústrias de pescados, representando um desperdício significativo de recursos e resultando em altas taxas de contaminação ambiental (SILVA, 2014).

A utilização integral do pescado ainda não é uma prática usual nas indústrias, sendo que, aproximadamente $60 \%$ do pescado processado é responsável pela geração de resíduos, enquanto apenas $40 \%$ é designado para o consumo (CHALAMAIAH et al., 2012; TAHERGOABI et al., 2013).

Resíduo de pescado é um termo referente aos subprodutos e remanescentes de valor comercial relativamente baixo, resultantes do processamento de espécies aquáticas. Em relação ao peixe, o material residual é constituído por sobras obtidas do processamento de filés ou outros cortes que resultam em remanescentes como: carne, cabeça, pele, ossos, escamas e vísceras (OETTERER, 2002).

A tilápia do Nilo (Oreochromis niloticus L.) é uma das espécies mais cultivadas no mundo, seu rendimento de filé pode atingir entre 30 e $40 \%$ do peso do animal. O remanescente é considerado resíduo de baixo valor comercial, que são subutilizados ou descartados pelas indústrias processadoras de filés (BOSCOLO; FEIDEN, 2007).

Essa matéria prima pode ser comercializada ou utilizada para elaboração de produtos secundários de alta qualidade nutricional através de tecnologias adequadas. A partir disso, espera-se que esses produtos sejam uma maneira para a diminuição de problemas de má nutrição, carência ou 
deficiência de proteínas de elevado valor nutricional na dieta alimentar e na redução dos impactos negativos gerados pelo descarte da atividade industrial no meio ambiente (PIRES et al., 2014). Objetivou-se com essa revisão de literatura, realizar um estudo sobre a aplicação dos resíduos de filetagem de tilápia na tecnologia de alimentos.

\section{DESENVOLVIMENTO}

\section{Produção, consumo e características gerais}

Segundo a Associação Brasileira de Piscicultura, a produção nacional em 2017 foi de 691.700 toneladas de peixes e no ano de 2018 foi produzido cerca de 722.560 toneladas, tendo um aumento de 4,5\%. O relatório aponta que a tilápia teve produção de 400.280 toneladas produzidas em 2018, com crescimento de $11,9 \%$ em relação ao ano de 2017 , representando $(55,4 \%)$ da produção brasileira de peixes de cultivo. Essa produção coloca $\circ$ Brasil entre os quatro maiores produtores de tilápia do mundo, atrás de China, Indonésia e Egito, e à frente de Filipinas e Tailândia (PEIXE BR, 2019).

A Organização Mundial da Saúde (OMS) recomenda o consumo per capita de $12 \mathrm{Kg}$ de peixe por ano por habitante, sendo que a média global de consumo per capita de $18 \mathrm{Kg}$ /ano (MPA, 2013). O brasileiro consumiu menos de $10 \mathrm{~kg}$ de peixes em 2018, estando abaixo do recomendado da FAO de 12 $\mathrm{kg} / \mathrm{hab} / \mathrm{ano}$, e inferior à média mundial (PEIXE BR, 2019).

O consumo de carne de peixe pelo brasileiro, quando comparado a países da Europa, é classificado como baixo, já que fora do Brasil o consumo per capita chega a ser o dobro. Entretanto, esses dados variam de acordo com a estados brasileiros, pois em alguns estados do Norte do país, o consumo de peixe chega a representar $70 \%$ do total de carnes. Quanto à preferência pela variedade de peixes, normalmente, os consumidores optam pelas espécies mais comuns em suas regiões (LOPES; OLIVEIRA; RAMOS, 2016).

A tilápia do Nilo vem se destacando como uma das espécies mais cultivadas no Brasil e no mundo nos últimos anos, e essa ascensão forte na 
aquicultura brasileira se deve às suas características, pois a espécie tem boa adaptabilidade, resistência, facilidade na reprodução, altas taxas de crescimento e sobrevivência. (BARROSO et al., 2015). Já a preferência relacionada ao consumidor, está associada à sua carne branca firme, sabor delicado, baixo teor de gordura e calorias e ausência de ossos em forma de "Y" (SILVA et al., 2016).

Alguns estados brasileiros possuem melhores níveis de produção por terem cadeias em estágios mais avançados de estruturação, sendo autossustentáveis nos insumos básicos e no beneficiamento. No entanto, mesmo apresentando condições naturais privilegiadas para o desenvolvimento das mais diversas modalidades aquícolas, outros estados são menos competitivos e necessitam de maiores investimentos e inciativa de novas políticas para produzir mais eficientemente (BRABO, 2014).

\section{Resíduos de peixe}

Os resíduos são as partes não aproveitadas de uma determinada produção ou partes descartadas por limitações tecnológicas ou mercadológicas. Os resíduos se caracterizam por não apresentar valor de mercado e o seu descarte acarretar danos ao meio ambiente quando feito de forma inadequada (REBOUÇAS et al., 2012).

A tilápia geralmente é comercializada na forma de peixe inteiro ou em filés (frescos ou congelados), sendo a filetagem sua principal forma de comercialização, pois esses produtos são os que apresentam importância significativa para mercado interno e exportação. Com isso, as indústrias de processamento, utilizam essa parte cárnea e descartam a espinha dorsal, músculo abdominal ventral, músculo hipaxial profundo e aparas finais de filé (GJERDE et al., 2012; OLIVEIRA FILHO et al., 2012; VIDAL et al., 2011). De acordo com Kubitza e Campos (2006), para cada $1 \mathrm{~kg}$ de tilápia processada, aproximadamente $350 \mathrm{~g}$ residual com carne aderida na carcaça são gerados. Com isso, a busca por características desejáveis para a comercialização, somando com o baixo rendimento de filés (30\%), tem como consequência, a 
geração de uma quantidade significativa de resíduo durante o processamento (MONTEIRO et al., 2014).

Os locais que vendem pescados in natura são as maiores fontes geradoras de resíduos, geralmente são locais carentes de tecnologias voltadas ao aproveitamento de resíduo e com grande processamento de subprodutos e quantidade elevada de descarte (GALVÃO; OETTERER, 2014). Apesar de várias atividade de processamento de pescados ocorrer em maiores quantidades nas indústrias e haver muita dispersão de resíduos em efluentes, vale ressaltar, que, devido ao processo de modernização e a necessidade de mitigar impactos ambientais, houve uma crescente necessidade de desenvolver estratégias de processamento para maximizar o reaproveitamento dos componentes funcionais presentes nos resíduos comestíveis de pescado e os destinar à fabricação de produtos de alto valor nutricional (TAHERGORABI et al., 2013).

Os mercados públicos que comercializam pescados também são grandes geradores de resíduos, isso porque os comerciantes realizam filetagem e outros tipos de cortes, lavagem dos peixes, utensílios e instalações, produzindo uma quantidade considerável de resíduos de pescado (LEITE et al., 2016; GUIMARÃES et al., 2018).

A falta de reconhecimento do potencial de aproveitamento integral dessa matéria prima, ainda é a principal barreira para utilização na elaboração de outros produtos (CASTRO-MUÑOZ et al., 2016). Segundo o estudo de Dallabona (2013), o filé de tilápia do Nilo possui cerca de $78,8 \%$ de umidade, $16,3 \%$ de proteína, 3,2\% de lipídios e 1,0\% de cinzas.

\section{Poluição ambiental e aspectos sustentáveis}

Durante as diversas etapas da cadeia produtiva de diversos segmentos da indústria alimentícia, é gerada uma quantidade significativa de resíduos, seja, desde a produção inicial até a sua comercialização. Diante desse fato, as indústrias alimentícias tanto de origem animal, quanto vegetal vem tendo uma crescente pressão para se tornarem responsáveis com os resíduos 
descartados no meio ambiente e os impactos causados, sendo requeridas a viabilizarem formas diferentes de utilização destes resíduos (AGUIAR; GOULART, 2014).

Quando os resíduos são lançados no meio ambiente sem o tratamento adequado, podem ocasionar sérias alterações nas características da água, ar e do solo, e como consequência podem ser nocivos e altamente prejudiciais para a vida aquática e terrestre aonde são descartados (LIMA, 2013). A principal consequência desse descarte é a eutrofização e redução de oxigênio, o que afeta a turbidez da água (LIN e YI, 2003). Pois, os resíduos descartados nos efluentes, causam a acumulação dos sólidos em suspensão, que podem ocasionar a redução da quantidade de luz que entram na água, prejudicando a vida dos organismos aquáticos. Esses materiais poluentes das indústrias pesqueiras são ricos em óleos, que quando lançados em ambiente aquático prejudicam a transferência de oxigênio na água, uma vez que se concentram na superfície da água (CHOWDHURY; VIRARAGHAVAN; SRINIVASAN, 2010).

Ao descartar no solo, terá impactos nocivos sobre a microflora e haverá a produção de materiais putrefativos e odores fétidos que por sua vez atrairão pragas urbanas e vetores que são importantes pelas inúmeras doenças que podem ser transmitidas ao homem e aos animais. Além disso, esse material orgânico em decomposição também é o habitat de microrganismos saprófitos (bactérias, protozoários e fungos) e atrai macrovetores (moscas, baratas e ratos) (KAUR et al., 2010).

A principais pragas urbanas, como ratos, baratas e moscas, e também animais predadores de pescado, como a garça e outras aves, oferecem risco contaminação cruzada entre os produtos expostos e as sobras incorretamente descartadas no ambiente, bem como, nos locais de comercialização, devido ao armazenamento incorreto e ausência de conhecimento de boas práticas manipulação (LEITE; SUCASAS; OETTERER, 2016).

Transformar esses resíduos sólidos descartáveis e poluentes em produtos com valor agregado é importante como base para o desenvolvimento 
sustentável do mundo moderno, reduzindo o desperdício de matéria-prima e promovendo a reciclagem para ter processos mais econômicos e com menor impacto ambiental (LIMA, 2013). Por se tratar de um resíduo com elevado valor biológico é importante desenvolver formas viáveis para a fabricação de subprodutos com alto valor agregado, pois ainda tem sido realizado de forma irregular. As tecnologias devem visar o conjunto, promovendo a otimização da utilização dos resíduos, juntamente com uso de tecnologias limpas, buscando contaminação zero no meio ambiente e aproveitamento integral (PIRES et al., 2014).

\section{Utilização na tecnologia de alimentos}

Nos últimos tempos a indústria de alimentos vem tendo como principal desafio a produção de alimentos processados com valor nutricional adicional, que tenha propriedades acessíveis e boa característica sensorial (MONTEIRO et al., 2018). A utilização de resíduos de peixes, além de aplicar o conceito de sustentabilidade na produção, é uma opção para reduzir os custos, com elaboração de novos produtos, e consequentemente reduzir os resíduos orgânicos no meio ambiente (MAGALHÃES et al., 2019). O desenvolvimento de coprodutos é uma boa alternativa para atender as expectativas e anseios do consumidor moderno, que se preocupa com o consumo de alimentos diferenciados, como alimentos funcionais e alimentos que apresentam propriedades preventivas de doenças crônico-degenerativas (BARBOSA et al., 2010).

Durante a compra de produtos processados, é notável o interesse do consumidor nas informações presentes no rótulo, fazendo a associação da qualidade do valor nutricional, da marca, origem, presença do selo de inspeção e aspectos de sustentabilidade (MACIEL et al., 2013). Essa busca por informações das características de qualidade tem sido mais frequente pelos consumidores, principalmente por pessoas com maior grau de instrução/escolaridade, o que mostra o aumento da exigência (MANGAS et al., 2016). 
A destinação dos resíduos de peixe na tecnologia de alimentos pode ser classificada em dois grupos, o primeiro destinado a produção animal, podendo ser utilizados como ingrediente para a ração animal, em processo artesanal ou industrial. Geralmente o aproveitamento é feito com a produção de óleo, silagem, farinha de peixe, compostagem de peixes e também como fertilizantes. As partes aproveitadas nesse processo são: a cabeça, coluna vertebral., parte da carne aderida, pele e as escamas. Os resíduos aproveitados para alimentação humana são caracterizados pela utilização da carcaça com carne aderida e aparas obtidas durante a toalete dos filés, na maioria dos casos é feita pela produção de Carne Mecanicamente Separada (CMS), e a partir desse processamento são elaborados vários tipos de produtos como: empanados, formatados, embutidos e reestruturados (AYROZA, 2011; NUNES, 2011; PIRES et al., 2014).

Resultados sobre a composição centesimal da CMS de tilápia de diferentes pesquisas estão representadas na tabela 1 .

Tabela 1. Composição centesimal de Carne Mecanicamente Separada de tilápia de diferentes pesquisas

\begin{tabular}{ccccc}
\hline & \multicolumn{2}{c}{ Parâmetros (\%) } & & \multirow{2}{*}{ Fonte } \\
\cline { 1 - 4 } Proteína & Lipídios & Cinzas & Umidade & \\
\hline 10,7 & 12,9 & 1,0 & 74,7 & Sary et al., (2009) \\
14,6 & 4,66 & 0,8 & 79,0 & Bordignon et al. (2010) \\
14,0 & 6,27 & 1,1 & 78,3 & \\
21,0 & 2,3 & 0,7 & 76,0 & Kirschnik et al (2013) \\
12,4 & 10,6 & 1,7 & 75,0 & Bernadino Filho e Xavier (2019) \\
\hline
\end{tabular}

As pesquisas mostram que a CMS é uma matéria prima rica em nutrientes, com destaque para os valores de proteína (10,7 a 21\%) e lipídios (2,3 a 12,9\%). Esses nutrientes possuem alto padrão e quando aproveitadas, oferecem produtos de qualidade. Segundo Stansby (1967), as proteínas presentes na musculatura da tilápia podem variar de $15 \%$ a $20 \%$. Já os lipídios presentes na tilápia é composto principalmente por ácidos graxos monoinsaturados, poliinsaturados totais, saturados e ômega-3. A variação 
referente aos teores de lipídios, tem como causa mais recorrente a forma de limpeza da carcaça antes do processamento, pois a preservação do músculo abdominal aderido as carcaças da tilápia, pode acarretar em uma CMS rica em lipídios, pois esses tecidos são ricos em adiposidade (DALLABONA et al., 2013).

De acordo com os artigos pesquisados, os produtos mais desenvolvidos a partir da CMS, são: fishburguer, empanados, embutidos, almôndegas, entre outros. A boa aceitação sensorial e alto valor nutricional, são características comuns entre esses produtos, pois são uma fonte rica de nutrientes. Na Tabela 2, seguem diferentes produtos elaborados a partir CMS de tilápia.

Tabela 2. Produtos alimentícios elaborados a partir CMS de Tilápia

\begin{tabular}{cc}
\hline Produto & Fonte \\
\hline Nugget & Kirschnik (2007) \\
Bolinho e Fishburger & Sary et al., (2009) \\
Croquete & Bordignon et al., (2010) \\
Mortadela & Mélo et al. (2011) \\
Almôndegas & Oliveira, Cruz e Almeida, (2012) \\
Quenelle & Angelini et al., (2013) \\
Biscoitos e sopa de farinha de peixe & Barreto, Rocha e Ledo (2015) \\
Macarrão & Goes et al., (2016) \\
\hline
\end{tabular}

A aceitação sensorial de um produto é um aspecto importante, pois vai direcionar se o consumidor deverá aprovar a formulação. Em muitos trabalhos com elaboração de produtos utilizando CMS de tilápia, os autores buscam uma alternativa de inserir o pescado na alimentação infantil, atribuindo variações e agregando sabor com outros ingredientes secundários para conquistar esse público. Produtos como: embutido (SILVA et al., 2020), Almôndegas (LUSTOSA-NETO et al., 2018) e mortadela (MÉLO et. al., 2011), obtiveram bons índices de aceitabilidade para suas amostras e os autores classificaram a produção de CMS como uma alternativa para agregar valor aos resíduos e uma forma de oferecer a população alimentos para incentivar o consumo de peixe, principalmente nas escolas. O planejamento de cardápios é uma etapa que 
visa promover a formação da educação nutricional, através da introdução de bons hábitos alimentares, garantindo qualidade na alimentação escolar. É importante nesse processo inserir no planejamento de cardápio, o consumo de alimentos regionais, de acordo com a época de safra. Essas ações visam diminuir a influência de guloseimas e lanches gordurosos, que se tornaram hábito alimentar rotineiro das crianças, e a introdução de alimentos mais saudáveis e nutritivos. (ALVES et al., 2001; MEDEIROS, 1999).

\section{CONCLUSÃO}

Conclui-se que a utilização dos resíduos de filetagem de tilápia na tecnologia de alimentos pode minimizar as perdas econômicas das indústrias, contribuir para a mitigação do impacto ambiental e também aumentar a oportunidade de inserir o peixe na culinária através do desenvolvimento de produtos.

\section{REFERÊNCIAS}

AGUIAR, G. P. S.; GOULART, G. A. S. Produção de óleo e farinha a partir de coprodutos de pescado provenientes da bacia Tocantins-Araguaia. Revista Eletrônica Interdisciplinar, v. 1, n. 11, p. 67-71, 2014.

ALVES, R. C. C.; GALEZAZZI, M. A. M. Controle de qualidade e planejamento de cardápios. Programa Nacional de Alimentação Escolar. Brasília, 2001.

ANGELINI, M. F. C.; GALVÃO, J. A.; VIEIRA, A. M.; SAVAY-DA-SILVA, L. K.; SHIRAHIGUE, L. D.; CABRAL, I. S. R.; MODESTA, R. C. D.; GALLO, C. R.; OETTERER, M. Shelf life and sensory assessment of tilapia quenelle during frozen storage. Pesquisa Agropecuária Brasileira, v. 48, n. 8, p. 1080-1087, 2013.

AYROZA, L. M. S. Manual Técnico Piscicultura. Campinas: CECOR-CATISAA, 2011. 246p. 
BARBOSA, L.; MADI, L.; TOLEDO, M. A.; REGO, R. A. As tendências da alimentação. FEDERAÇÃO DAS INDÚSTRIAS DO ESTADO DE SÃO PAULO FIESP. Brasil Food Triends 2020. São Paulo, 2010, p. 39-47.

BARRETO, N. S. E.; ROCHA, J. B.; LEDO, C. A. S. Elaboração de biscoitos e sopa usando farinha de peixe. Arquivos de Ciências do Mar, v. 48, n. 1, p. 57-61, 2015.

BARROSO, R. M.; TENÓRIO, R. A; PEDROZA FILHO, M. X.; WEBBER, D. C.; BELCHIOR, L. S.; TAHIM, E. F.; CARMO, F. J.; MUEHLMANN, L. D. Gerenciamento genético da tilápia nos cultivos comerciais. Embrapa Pesca e Aquicultura. Palmas, TO. Série Documentos, v. 23. 64p. 2015.

BERNADINO FILHO, R.; XAVIER, L.C.A. Obtenção, rendimento e caracterização de CMS produzida com resíduos da filetagem de Tilápia do Nilo. Revista Brasileira de Agrotecnologia V. 9, № 2, p. 01-04, 2019.

BORDIGNON, A.C.; SOUZA, B.E.; BOHNENBERGER, C.C.H.; FIEDEN, A.; BOSCOLO, W.R. Elaboração de croquete de tilápia do Nilo (Oreochromis niloticus) a partir de CMS e aparas de corte em 'V' do filé e sua avaliação físicoquímica, microbiológica e sensorial. Acta Scientiarum. Animal Sciences, 32(1). 2010.

BOSCOLO, W.R.; FEIDEN, A. Industrialização de Tilápias. Toledo: GFM Gráfica e Editora, 2007, 272 p.

BRABO, M. F.; DIAS, B. C. B.; SANTOS, L. D.; FERREIRA, L. A., VERAS, G. C.; CHAVES, R. A. Competitividade da cadeia produtiva da piscicultura no Nordeste paraense sob a perspectiva dos extensionistas rurais. Informações Econômicas, (44)5:1-13. 2014.

CASTRO-MUÑOZ, R.; YÁÑEZ-FERNÁNDEZ, J.; FÍLA, V. Phenolic compounds recovered from agro-food by-products using membrane technologies: An overview. Food Chemistry, 213: 753-762. 2016.

CHAMALAIAH, M.; DINESH KUMAR, B.; HEMALATHA, R.; JYOTHIRMAYI, T. Fish protein hydrolysates: Proximate composition, amino acid composition, 
antioxidante activities and applications: A review. Food Chemistry, v. 135, p. 3020-3038, 2012.

CHOWDHURY, P.; VIRAGHAVAN, T.; SRINIVASAN, A. Biological treatment processes for fish processing wastewater - A review. Bioresource Technology, Vol. 101, Issue 2, January 2010.

DALLABONA, B. R.; KARAM, L. B.; WAGNER, R.; BARTOLOMEU, D. A. F. S.; MIKOS, J. D.; FRANSCISCO, J. G. P.; MACEDO, R. E.; KIRSCHNIK, P. G. Effect of heat treatment and packaging systems on the stability of fish sausage. Revista Brasileira de Zootecnia. v.42, n.12, 2013.

GALVÃO, J.; OETTERER, M. Qualidade e processamento de pescado. Rio de Janeiro: Elsevier, 2014. 237 p.

GJERDE, B.; MENGISTU, S.B.; ØDEGÅRD, J.; JOHANSEN, H.; ALTAMIRANO, D.S. Quantitative genetics of body weight, fillet weight and fillet yield in Nile tilapia (Oreochromis niloticus). Aquaculture, v.342-343, p.117-124, 2012.

GOES, E. S. R.; SOUZA, M. L. R.; MICHKA, J. M. G.; KIMURA, K. S.; LARA, J. A. F.; DELBEM, A. C. B.; GASPARINO, E. Fresh pasta enrichment with protein concentrate of tilapia nutritional and sensory characteristics. Food Science and Technology. v. 36, n.1, p.76-82, 2016.

GUIMARÃES, J.T.; SOUZAA, A.L.M.; BRÍGIDA, A.I.S.; FURTADO, A.A.L.; CHICRALA, P.C.M.S.; SANTOS, V.R.V.; ALVES, R.R.; LUIZ, D.B.; MESQUITA, E. F.M. Quantification and characterization of effluents from the seafood processing industry aiming at water reuse: A pilot study. Journal of Water Process Engineering, v.26, p.138-145, 2018.

KAUR, A.; VATS, S.; REKHI, S.; et al. Physico-chemical analysis of the industrial effluents and their impact on the soil microflora. Procedia Environmental Sciences, Vol. 2, Pages 595-599, 2010.

KIRSCHNIK, P. Avaliação da estabilidade de produtos obtidos de carne mecanicamente separarda de tilápia nilótica (Oreochromis niloticus). 
2007. Tese (Doutorado em Aquicultura) - Centro de Aqüicultura. Universidade Estadual Paulista, Jaboticabal.

KIRSCHNIK, P.G.; TRINDADE, M.A.; GOMIDE, C.A.; MORO, M.E.G.; VIEGAS, E.M.M. Estabilidade em armazenamento da carne de tilápia-do-nilo mecanicamente separada, lavada, adicionada de conservantes e congelada. Pesquisa Agropecuária Brasileira, 48(8): 935-942. 2013.

KUBITZA, F.; CAMPOS, J.L. Aquicultura no Brasil. Conquistas e Desafios. Panorama da Aquicultura, v.25, n.150, p.11-13, 2015.

LeITE, S. B. P.; SuCASAS, L. F. A.; OetTERER, M. Resíduos da comercialização de pescado marinho - volume de descarte e aspectos microbiológicos. Revista Brasileira de Tecnologia Agroindustrial, v.10, n.1, p.2112-2125, 2016.

LIMA, L. K. F. Reaproveitamento de Resíduos Sólidos na Cadeia Agroindustrial do Pescado. Palmas: Embrapa, 2013.

LIN, C.K.; YI, Y. Minimizing environmental impacts of fresh water aquaculture and reuse of pond effluents and mud. Aquaculture (Amsterdam, Netherlands), 226(1-4): 57-68. 2003.

LOPES, I. G.; OLIVEIRA, R. G.; RAMOS, F. M. Perfil do consumo de peixes pela população brasileira, Biota Amazônia, Macapá, v. 6, n. 2, p. 62-65, 2016.

LUSTOSA-NETO, A.D.; NUNES, M.L.; MAIA, L.P.; BARBOSA, J.M.; LIRA, P.P.; FURTADO-NETO, M.A.A. Almôndegas de pirarucu e tilápia nilótica: caracterização e aplicação na merenda escolar, Acta of fisheries and aquatic resources, 6(2): 1-12. 2018.

MACIEL, E. S. et al. Aplication of exploratory factor analysis to asses' fish consumption in a university community. Food Science and Tecnology, v.33, n.1, p.99-106, 2013.

MAGALHÃES, A.O.; MÁRSICO, E.T.; SOARES JÚNIOR, M.S.; MONTEIRO, M.L.G. Evaluation of the technological quality of snacks extruded from broken 
grains of rice and mechanically separated tilapia meat flour. Boletim do Instituto de Pesca ,45(2): e429, 2019.

MANGAS, F. P et al. Caracterização do perfil dos consumidores de peixe no município de Belém, estado do Pará, Brasil. Revista em Agronegócio e Meio Ambiente, v. 9, n. 4, p. 839- 857, 2016.

MEDEIROS, D. D. Manual do conselho de alimentação escolar. Fundo Nacional de Desenvolvimento da Educação. Brasília, 1999.

MÉLO, H. M. G.; MOREIRA, R. T.; DÁLMAS, P. S.; MACIEL, M. I. S.; BARBOSA, J. M.; MENDES, E. S. Viabilidade da utilização da carne mecanicamente separada (CMS) de Tilápia do nilo na elaboração de um produto tipo "mortadela". ARS Veterinaria, v. 27, n. 1, p. 22-29, 2011.

MONTEIRO, M.L.G.; MÁRSICO, E.T.; SOARES JUNIOR, M.S.; DELIZA, R.; OLIVEIRA, D.C.R.; CONTE-JUNIOR, C. Tilapia-waste flour as a natural nutritional replacer for bread: a consumer perspective. PLoS One, 13(5): 2018.

MPA (Ministério da Pesca e Aquicultura). Boletim Estatístico da Pesca e Aquicultura/Brasil. 2011. Brasília. v. 3, 101p, 2013.

NUNES, M. L. Farinha de pescado. In: GONÇALVES, A. A. Tecnologia do Pescado: Ciência, Tecnologia, Inovação e Legislação. São Paulo: Editora Atheneu, 2011, p. 362-371.

OETTERER, M. Industrialização do pescado cultivado. Guaíba: Livraria e Editora Agropecuária, p. 200, 2002.

OLIVEIRA FILHO, P.R.C.; VIEGAS, E.M.M.; KAMIMURA, E.S.; TRINDADE, M.A. Evaluation of physicochemical and sensory properties of sausages made with washed and unwashed mince from Nile tilapia by-products. Journal of Aquatic Food Product Technology, 21(3): 222-237. 2012.

OLIVEIRA, M. C.; CRUZ, G. R. B.; ALMEIDA, N. M. Características microbiológicas, físico-químicas e sensoriais de "almôndegas" à base de polpa de Tilápia (Oreochromis niloticus). Ciências biológicas e da saúde, v. 14, n. 1, p. 37-44, 2012. 
PEIXE BR- Associação Brasileira de Piscicultura. Anuário Peixe BR da Piscicultura 2019. São Paulo: Associação Brasileira de Piscicultura, 2019.138 p.

PIRES, D.R.; MORAIS, A.C.N.; COSTA, J.F.; GÓES, L.C.D.S.A. Aproveitamento do resíduo comestível do pescado: Aplicação e viabilidade. Revista Verde de Agroecologia e Desenvolvimento Sustentável, 9(5): 34 46. 2014.

REBOUÇAS, M.C.; RODRIGUES, M.C.P.; CASTRO, R.J.S.; VIEIRA, J.M.M. Caracterização do concentrado protéico de peixe obtido a partir dos resíduos da filetagem de tilápia do Nilo. Semina: Ciências Agrárias, Londrina, v. 33, n. 2, p. 697-704, 2012.

SARY, C., FRANCISCO, J. G. P., DALLABONA, B. R., MACEDO, R. E. F. M., GANECO, L. N., KIRSCHNIK, P. G. Influência da lavagem da carne mecanicamente separada de tilápia sobre a composição e aceitação de seus produtos. Rev. Acad., Ciênc. Agrar. Ambient., 7(4): 423-432. 2009.

SILVA, A.R.; ARCANJO, N.M.O.; JERÔNIMO, H.M.A.; MARTINS, A.C.S.; SILVA; R.S.; VIERA, V.B. Elaboração e índice de aceitabilidade de embutido obtido a partir do resíduo de tilápia (Oreochromis niloticus L.). Rev.Bras.de Gestão Ambiental. 14(01)64-68. 2020.

SILVA, J. F. X.; RIBEIRO, K.; SILVA, J. F.; CAHÚ, T. B.; BEZERRA, R. S. Utilization of tilapia processing waste for the production of fish protein hydrolysate. Animal Feed Science and Technology, v. 196, p. 96-106, 2014.

SILVA, L.M.; SAVAY-DA-SILVA, L.K.; ABREU, J.G.; FIGUEIREDO, E.E.S. Determinação de índices morfométricos que favorecem o rendimento industrial de filés de tilápia (Oreochromis niloticus). Boletim do Instituto de Pesca, 42(1): 252-257. 2016.

STANSBY, M.E. Proximate Composition of fish. Fish in Nutrition. 1962. 5561. 
TAHERGORABI, R.; BEAMER, S.K.; MATAK, K.E.; JACZYNSKI, J. Chemical properties of $x-3$ fortSified gels made of protein isolate recovered with isoelectric solubilisation/precipitation from whole fish. Food Chemistry, n.139, p.777-785, 2013.

VIDAL, J.M.A.; RODRIGUES, M.C.P.; ZAPATA, J.F.F.; VIEIRA, J.M.M. Concentrado protéico de resíduos da filetagem de tilápia-do-nilo (Oreochromis niloticus): caracterização físico-química e aceitação sensorial. Ciência Agronômica, 42(1):7. 2011. 